\title{
Surgical treatment for heart failure: cell-based therapy with engineered tissue
}

\author{
Jordan J. Lancaster ${ }^{1,2}$, Jen Watson Koevary ${ }^{1,3}$, Ikeotunye Royal Chinyere ${ }^{1,2}$, Sherry L. Daugherty ${ }^{1,2}$, \\ Kenneth A. Fox ${ }^{4}$, Steven Goldman ${ }^{1,2}$ \\ 'Sarver Heart Center, University of Arizona, Tucson, AZ 85724, United States. \\ ${ }^{2}$ Department of Medicine, University of Arizona, Tucson, AZ 85724, United States. \\ ${ }^{3}$ Department of Biomedical Engineering, University of Arizona, Tucson, AZ 85724, United States. \\ ${ }^{4}$ Department of Surgery, University of Arizona, Tucson, AZ 85724, United States.
}

Correspondence to: Prof. Jordan J. Lancaster, Sarver Heart Center, University of Arizona, 1501 North Campbell Avenue, Tucson, AZ 85724, United States. E-mail: Lancaste@email.arizona.edu

How to cite this article: Lancaster JJ, Koevary JW, Chinyere IR, Daugherty SL, Fox KA, Goldman S. Surgical treatment for heart failure: cell-based therapy with engineered tissue. Vesse/ P/us 2019;3:34. http://dx.doi.org/10.20517/2574-1209.2019.16

Received: 23 May 2019 First Decision: 3 Jul 2019 Revised: 22 Jul 2019 Accepted: 30 Aug 2019 Published: 17 Sep 2019

Science Editor: Mario F. L. Gaudino Copy Editor: Jia-Jia Meng Production Editor: Jing Yu

\begin{abstract}
This review will outline cell-based therapy for heart failure focusing on tissue engineering to deliver cells to the damaged heart. We will present an overview of the central approaches focusing on pluripotent stem cell-derived cells, mechanisms of action, autologous vs. allogeneic cell approaches, immunologic modulation, and safety considerations. We will outline the progress that has been made to-date and define the areas that still need to be investigated in order to advance the field.
\end{abstract}

Keywords: Heart failure, induced pluripotent stem cells, tissue engineering

\section{INTRODUCTION}

The ability to differentiate specialized functional cells from pluripotent stem cells (PSCs) has opened up the possibility of new therapeutic approaches that provide the functional units to solve the underlying causes of disease. Work using cells differentiated from embryonic PSCs first appeared 1998 when Jamie Thomson and colleagues published a report of deriving embryonic stem cell lines from human blastocyts ${ }^{[1]}$. This same laboratory described creating induced PSC lines from human somatic cells in $2007^{[2]}$. In 2012, the Nobel Prize in Physiology or Medicine was awarded to John B. Gurdon and Shinya Yamanaka for

cc) (i) The Author(s) 2019. Open Access This article is licensed under a Creative Commons Attribution 4.0 sharing, adaptation, distribution and reproduction in any medium or format, for any purpose, even commercially, as long as you give appropriate credit to the original author(s) and the source, provide a link to the Creative Commons license, and indicate if changes were made. 
the discovery that mature adult differentiated somatic cells can be reprogrammed to a pluripotent state to create an unlimited source of any cell in the body. The ability to generate human induced PSC-derived cardiomyocytes (PSC-CMs) from adult cells has further broadened interest and study in the use of these cells in the heart. A number of investigators are now culturing these cells, developing methods to maintain differentiated cell phenotype, and studying healthy and diseased human cardiomyocytes ${ }^{[3-6]}$. Much of this work looks at reprogramming somatic cells from healthy and diseased donors to study known mutations and deficiencies of cardiomyocytes, as well as identify potential treatments. Hurdles regarding target identification and drug development have been attributed to variability in phenotype, thus the growing body of work in this area ${ }^{[7,8]}$.

Prior to the development of PSCs, the early work with cell-based therapy for acute myocardial infarction and chronic heart failure (CHF) involved administering varying adult somatic cell populations. With the exception of the skeletal myoblasts ${ }^{[9]}$, these approaches proved safe but had limited therapeutic efficacy with respect to improved cardiac function and structural remodeling ${ }^{[10,11]}$. With the advent of PSCs it became possible for investigators to create the functional building blocks of the heart allowing for the development of tissue engineering (TE) approaches, cellular reprogramming, and gene editing to optimize the delivery of tissue function specific cells to the damaged heart ${ }^{[12-23]}$.

\section{AUTOLOGOUS VS. ALLOGENEIC PREPARATIONS}

Early in the evolution of cell-based therapies there was enthusiasm to use autologous approaches with the patient's own cells so as to avoid immune rejection. However, it has become clear that limitations with autologous approaches exist: sample collection and preparation from individual patients is timeconsuming, costly and may ultimately lack efficacy because of problems with cellular genome stability and regenerative potential. To overcome these limitations, allogeneic approaches have been adopted using screened, optimal donors. This donor vetting improves both the quality and potency of the cell product, increases cell availability, and decreases cost through scaled manufacturing. The paradigm switch from autologous to allogeneic was observed with the first clinical trial using PSC derived cells for age-related macular degeneration, which started with autologous preparations but subsequently changed to using allogeneic cells ${ }^{[24]}$.

\section{IMMUNE CONSIDERATIONS}

Immunologic rejection is something relevant for all proposed cell-based therapies ${ }^{[25]}$. The concept of accounting for the immune system is based on the belief that PSC derived cells are not immuneprivileged because of Human Leukocyte Antigen (HLA)/ABO antigens. Investigators have suggested that the expression of these antigens in PSC-derived cells equates them with any other organ transplants, all of which require immune suppression ${ }^{[26]}$. Immunosuppressive agents such as cyclosporine and tacrolimus have been used for solid organ transplant and described extensively in pre-clinical studies of TE preparations. However, they are costly, may be cytotoxic, and cause adverse effects. There is a clinical trial in Japan using PSC-CMs in patients with CHF patients where the patients receive non-HLA mapped allogeneic cardiomyocytes and are given immune suppression ${ }^{[27]}$. The use of HLA mapping is one option by which to circumvent immunosuppressive agents; allogeneic cell lines of HLA-typed donors could be generated to maximally match each recipient, though an identical match is statistically improbable. Such a strategy would require creating and maintaining large cell banks. Generating personalized products for individual patients from the bank would be expensive and require HLA typing of every patient. The ability to edit candidate therapeutic cell lines is also being explored, to make a hypo-immune cell, one that would be considered "universal". Each cell line could be edited to remove HLAs while still maintaining markers of identity so as to go undetected as foreign by the immune system, theoretically eliminating the need for 
immunosuppression ${ }^{[28]}$. Gene editing may prove valuable in the future to generate cell therapy candidates that integrate or persist in the host without losing potency.

\section{ENGINEERED TISSUE TO TREAT HEART FAILURE}

The development of cell-based TE approaches is exciting and in essence has the potential to generate a therapeutic tissue with properties and function of the myocardium ${ }^{[13]}$. Investigators have constructed tissue patches that could be manipulated with respect to anisotropic components, degree of electrical conductance, and mechanical qualities such as cardiomyocyte alignment and electromechanical coupling or using decellularized starting material as a substrate ${ }^{[2,30]}$. Cardiac patches have been engineered with nanotopographically-defined hydrogels meant to enhance cardiac regeneration by providing functional cell-material interfaces ${ }^{[31]}$. Three-dimensional (3-D) printing has also been utilized to generate TE scaffolds by organizing special patterning of stem cells. The 3-D generated patches proved sufficient to promote rapid vascularization with the potential to improve cardiac function and reverse maladaptive left ventricular (LV) remodeling ${ }^{[32]}$. Cardiac scaffolds have been made from electro-conductive acid-modified silk fibroinpoly (pyrrole) substrates. With PSC derived cardiomyocytes these grafts showed enhanced gap junction distribution and cardiomyocyte maturation ${ }^{[33,34]}$.

Lancaster et al ${ }^{[35]}$ have developed a TE cardiac patch composed of a bioabsorbable scaffold embedded with human neonatal fibroblasts and PSC-CMs that is implanted on the epicardial surface of the heart to treat CHF. The fibroblasts proliferate and synthesize glycosaminoglycans, collagen, elastin, fibronectin and laminin while providing a secretome of growth factors and cytokines. The fibroblasts support the incorporation of the cardiomyocytes into the scaffold and the cardiomyocytes provide additional complementary secretomes. This cardiac patch increases myocardial blood flow, reverses maladaptive LV remodeling, activates endogenous growth factor secretion, recovers hibernating myocardium and improves LV function and improves electrical propagation through the previously scarred myocardium and enhances electrical stability of the healthy tissue-scar interfac ${ }^{[14-16,35]}$. The specific growth factors are angiopoietin-1, $\beta$-myosin heavy chain, connexin 43 , insulin like growth factor and vascular endothelial growth. This patch is robust; it is easy to handle for open surgical or minimally invasive implantation. Figure 1 and the Supplementary Video 1 demonstrate implantation on the epicardium in an infarcted Yucatan mini swine via a mini median sternotomy where the patch is positioned to broadly cover all damaged tissue. We envision that multiple patches and/or multiple patch applications could be applied if needed. Table 1 summarizes previous work done with TE approaches using iPSC-CMs to treat heart failure. The epicardium may play an important role in regulating regeneration and may be the catalyst of the beneficial effects we and other investigators see when we implant cell-seeded scaffolds on the epicardium $^{[36-38,48-50]}$.

Implanting TE scaffolds in preclinical animal models of heart failure has proven safe. The data have shown no teratoma formation, accompanied by hemodynamic benefits, and attenuated LV remodeling, however data show limited long-term engraftment with the implanted cells despite providing immune suppression ${ }^{[20]}$. Menasché et al ${ }^{[19]}$ have transplanted PSC-derived cardiac progenitor cell fibrin patches in 6 patients with decreased LV function and showed that the treatment was safe. No arrhythmias were noted by ICD interrogations and no tumors were reported ${ }^{[19]}$. Based on this work, these investigators performed a second trial of 10 patients, but these results are still forthcoming. To date, there is only one clinical trial has commenced using PSC-CMs to treat patients in CHF; this trial is currently ongoing in Japan ${ }^{[27]}$. Cardiothoracic surgeons are implanting cell sheets on the epicardial surface of the heart in immune-suppressed patients. Table 1 summarizes some of the TE scaffolds developed to treat heart failure progressing from early work with rat neonatal cardiomyocytes to the clinical trial in Japan with PSC-CMs on cell sheets. 

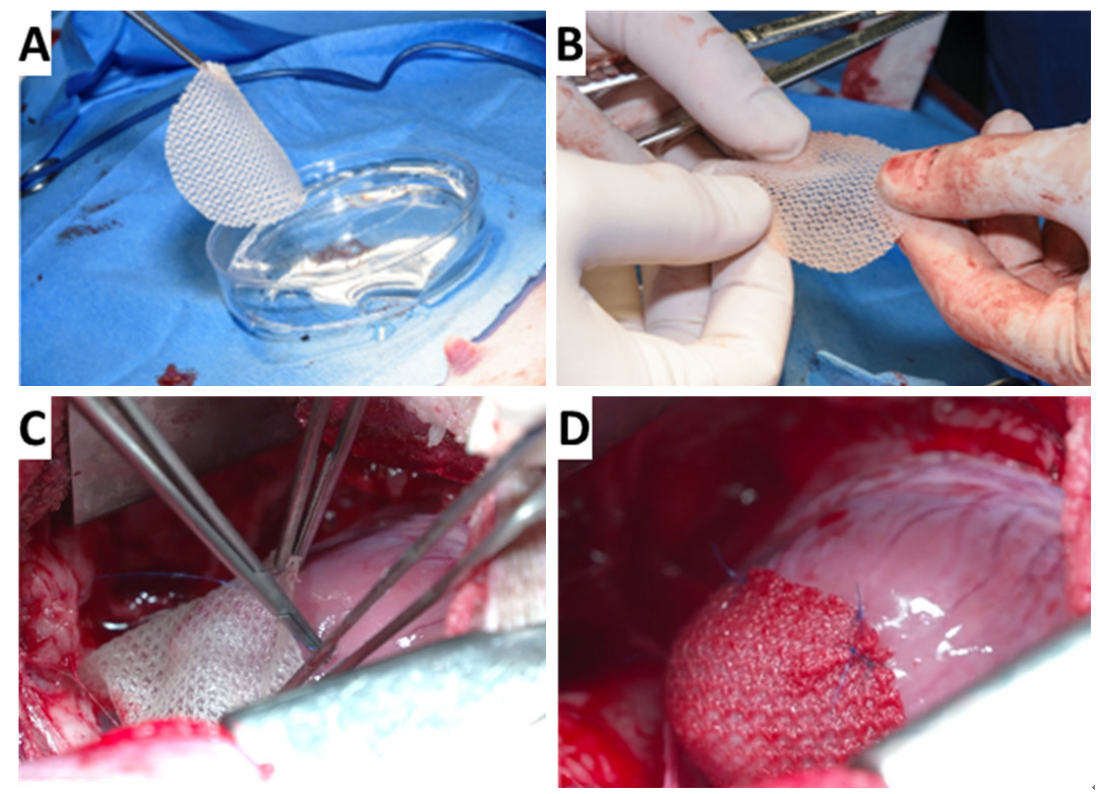

Figure 1. Intra-operative implant of cardiac patch in mini-swine one month after myocardial infarction. A: the patch is picked up by surgeon (KF) in the operating room; B: easily handled by surgeons prior to implantation; C: implanted in mini-swine through a mini median sternotomy; D: close up view of the patch successfully implanted on the heart

Table 1. Summary of TE approaches using pluripotent derived cardiac cells for heart failure

\begin{tabular}{|c|c|c|c|c|}
\hline Cell type & Auto/allo & Scaffold & Stage & Investigator ${ }^{\text {(Ref) }}$ \\
\hline Neonatal rat cardiomyocytes & Auto & EHT & Pre-clinical & Zimmerman et al. ${ }^{[39]}$ \\
\hline Neonatal rat cardiomyocytes & Auto & Bioabsorbable polymer & Preclinical & Lancaster et al. ${ }^{[15,16]}$ \\
\hline Vascular smooth muscle & Auto & PCLA & Pre-clinical & Matsubayashi et al. ${ }^{[40]}$ \\
\hline Skeletal myoblasts & Auto & Cell sheet & Clinical & Sawa et al. ${ }^{[41]}$ \\
\hline Skeletal myoblasts & Auto & Cell sheets & Clinical & Yoshikawa et al. ${ }^{[42]}$ \\
\hline ES derived cardiac progenitor & Allo & Fibrin & Clinical & Menasché et al..$^{[19]}$ \\
\hline PSC-CMs & Allo & Cell sheets & Pre-clinical & Kawamura et al. ${ }^{[20]}$ \\
\hline PSC-CMs & Allo & EHT & Pre-clinical & Yorgan et al. ${ }^{[43]}$ \\
\hline Bone marrow stem cells & Auto & Fibrin & Pre-clinical & Liu et al. ${ }^{[44]}$ \\
\hline Mesenchymal progenitor cells & Allo & Fibrin & Pre-clinical & Godier-Furemont et al. ${ }^{[45]}$ \\
\hline PSC-CMs & Allo & 3-D scaffold & Pre-clinical & Gao et al. ${ }^{[17]}$ \\
\hline ES cardiomyocytes/progenitors & Auto & Fibrin & Pre-clinical & Liau et $a l^{[29]}$ \\
\hline Human cardiac progenitor & Allo & hdECM & Pre-clinical & Jang et $a l_{.}^{[32]}$ \\
\hline PSC-CMs & Allo & Silk fibrion-poly (pyrrole) & Pre-clinical & Tsui et al. ${ }^{[33]}$ \\
\hline PSC-CMs & Allo & Cell sheets & Pre-clinical & Matsuura et al. ${ }^{[46]}$ \\
\hline PSC-CMs & Allo & Cell Sheets & Pre-clinical & Sasagawa et al..$^{[47]}$ \\
\hline PSC-CMs & Allo & Bioabsorbable polymer & Pre-clinical & Lancaster et al. ${ }^{[35]}$ \\
\hline PSC-CMs & Allo & Cell sheets & Clinical & Cyranoski/Sawa ${ }^{[27]}$ \\
\hline
\end{tabular}

TE: tissue engineering; Allo: allogeneic; Auto: autologus; hdECM: decellularized extracellular matrix; ES: embryonic stem; EHT: engineered heart tissue; PSC-CMs: human induced pluripotent stem cell-derived cardiomyocytes; PCLA:sponge polymer of epsilon-caprolactone-coL-lactide reinforced with knitted poly-L-lactide fabric

\section{MECHANISMS OF ACTION OF CELL-BASED THERAPY}

It is likely that the mechanism of action that improves LV function with cell-based therapy is multi-modal and is shaped by the fate of the cells, as the cells can be intended as either integrating or non-integrating. Integrating cells directly replace lost myocardium and theoretically contribute to mechanical function. Non-integrating approaches are transient in that the cells persist for days, weeks or months, imparting a beneficial effect, before ultimately being cleared from the tissue. In both integrating and non-integrating 
approaches, a secretome of soluble factors such as growth factors, exosomes, and miRNAs are thought to be responsible for the beneficial effects ${ }^{[48-50]}$. The specific paracrine stimulation may vary by implanted cell type and may be modulated by the cell culture environment, delivery platform, and other relevant variables.

In pre-clinical studies Lancaster et al. ${ }^{[14-16,35]}$ did not immune suppress their animals and long-term physiologic benefits were seen when implanting human xenografts in immune-competent animals. The transplanted PSC-CMs did not persist beyond four weeks post-implantation, but the initial functional benefit continued to persist at ten weeks post-implantation ${ }^{[35]}$.

\section{SAFETY CONSIDERATIONS}

The use of PSC-derived cells offer potential as a source for therapeutic advancements in all tissues, not just the heart. The safety of these cell preparations when implanted in patients is obviously important. The potential for tumorigenicity resulting from undifferentiated PSCs contaminants is a concern, particularly with integrating cell preparations. The Food and Drug Administration requires extensive preclinical testing for teratoma formation before approving PSC-derived preparations for clinical use. During somatic skeletal myoblasts injections into the myocardium, ectopic foci were established that generated VT from spontaneously depolarizing cells ${ }^{[0]}$. The finding of increased incidence of ventricular tachyarrhythmia has also been reported with human embryonic stem cell-derived cardiomyocyte injections into non-human primates and swine hearts ${ }^{[1,52]}$. Interestingly in preclinical studies with PSC-CMs TE scaffolds implanted on the epicardium, the animals remain in normal sinus rhythm without any arrhythmias ${ }^{[20,35]}$.

\section{PROSPECTS FOR THE FUTURE}

Looking into the future to predict the next advances of TE approaches to treat CHF is difficult but while creating a cardiac patch has received a lot of interest, there are a number of other potential approaches. Investigators have proposed decellularizing entire hearts and then repopulating with new PSC-derived cells ${ }^{[53]}$. There are also efforts to use 3-D printing to print entire organs ${ }^{[54]}$. Synthesizing microvesicles such as exosomes or secretomes that are secreted from the PSC-derived cells are being explored as a way to bypass cell-based therapy and still retain the paracrine effect ${ }^{[48]}$. Some of the issues outlined previously need to be addressed such as the best strategies for immune suppression in patients, required maturity of PSC-derived cells, use of integrating or non-integrating approaches and duration of transplanted cell survival in order to result in the most beneficial effects. A recent review summarizes the "bottlenecks" for the future of TE cardiac scaffolds ${ }^{[55]}$. Despite these issues, we see a bright future for using TE approaches for regenerative cardiology and all of medicine. The FDA now has a rapid approval process for cell therapy and therapeutic TE products. The Regenerative Medicine Advanced Therapy designation of the 21st Century Cures Act is designed to help accelerate medical product development and bring new innovations and advancements to the patients who need them urgently ${ }^{[56]}$.

\section{CONCLUSIONS}

The availability of PSC-derived cells and ability to generate TE approaches have introduced a unique opportunity to develop novel strategies to treat patients. While there remain points of concern that need to be addressed with respect to PSC-derived therapy, such as defining the mechanisms of action and the potential need for immune suppression the field as a whole is moving forward and TE surgical therapies for regenerative cardiology are closer to reality today than ever before. 


\section{DECLARATIONS}

\section{Authors' contributions}

Conception, design, analysis and interpretation of the data: Lancaster JJ, Koevary JW, Chinyere IR, Daugherty SL, Fox KA, Goldman S

All the authors made substantial contributions to this article.

\section{Availability of data and materials}

Not applicable.

\section{Financial support and sponsorship}

This was supported by grants from The WARMER Foundation, the Department of Veterans Affairs, University of Arizona, Sarver Heart Center, The Martin and Carol Reid Family Charitable Remainder Trust and the NHLBI (T32 HL007249-43).

\section{Conflicts of interest}

Drs. Lancaster, Koevary, Goldman and Ms. Daugherty have a financial interest in Avery Therapeutics, a biotechnology company that is commercializing platform technologies to deliver cell-based therapies for clinical use. The other authors (Chinyere IR, Fox KA) report no conflicts.

\section{Ethical approval and consent to participate}

Not applicable.

\section{Consent for publication}

Not applicable.

\section{Copyright}

(C) The Author(s) 2019.

\section{REFERENCES}

1. Thomson JA, Itskovitz-Eldor J, Shapiro SS, Waknitz MA, Swiergiel JJ, et al. Embryonic stem cell lines derived from human blastocysts Science 1998;282:1145-7.

2. Yu J, Vodyanik M, Smuga-Otto K, Frane J, Antosiewicz-Bourget J, et al. Induced pluripotent stem cell lines derived from human somatic cells. Science 2007;318:1917-20.

3. Davis J, Davis C, Correll RN, Makarewich CA, Schwanekamp JA, et al. Tension-Based Model Distinguishes Hypertrophic versus Dilated Cardiomyopathy. Cell 2016;165:1147-59.

4. Eschenhagen T, Carrier L. Cardiomyopathy phenotypes in human-induced pluripotent stem cell-derived cardiomyocytes-a systematic review. Pflugers Arch 2019;471:755-68.

5. Tanaka A, Yuasa S, Node K, Fukuda K. Cardiovascular Disease Modeling Using Patient-Specific Induced Pluripotent Stem Cells. Int J Mol Sci 2015;16:18894-22.

6. Wang Y, Liang P, Lan F, Wu H, Lisooski L, et al. Genome Editing of Isogenic Human Induced Pluripotent Stem Cells Recapitulates Long QT Phenotype for Drug Testing. J Am Coll Cardiol 2014:64;451-9.

7. Mummery CL. Perspectives on the Use of Human Induced Pluripotent Stem Cell-Derived Cardiomyocytes in Biomedical Research. Stem Cell Rep 2018;11:1306-11.

8. Stillitano F, Hansen J, Kong CW, Karakikes I, Funck-Brentano C, et al. Modeling susceptibility to drug-induced long QT with a panel of subject-specific induced pluripotent stem cells. Elife 2017;6:e19406.

9. Menasche P, Hagège AA, Vilquin JT, Desnos M, Abergel E, et al. Autologous skeletal myoblast transplantation for severe postinfarction left ventricular dysfunction. J Am Coll Cardiol 2003:41;1078-83.

10. Fisher SA, Doree C, Mathur A, Martin-Rendon E. Meta-Analysis of Cell Therapy Trials for Patients with Heart Failure - An Update. Circ Res 2015;116:1361-77.

11. Nguyen PK, Rhee JW, Wu JC. Adult stem cell therapy and heart failure, 2000 to 2016: a systematic review. JAMA Cardiol 2016;1:831-41.

12. Muller-Ehmsen J, Whittaker P, Kloner RA, Dow JS, Sakoda T, et al. Survival and development of neonatal rat cardiomyocytes transplanted into adult myocardium. J Mol Cell Cardiol 2002;34:107-16.

13. Leor J, Amsalem JY, Cohen S. Cells, Scaffolds, and molecules for myocardial tissue engineering. Pharmacol Ther 2005;105:151-63. 
14. Thai HM, Juneman E, Lancaster JJ, Do R, Castellano L, et al. Implantation of a three-dimensional fibroblast matric improves left ventricular function and blood flow after acute myocardial infarction. Cell Transplant 2009;18:283-95.

15. Lancaster JJ, Juneman E, Hagerty T, Do R, Hicks M, et al. Viable fibroblast matric patch induces angiogenesis and increases myocardial blood flow in heart failure after myocardial infarction. Tissue Eng Pt A 2010;16:3065-73.

16. Lancaster JJ, Arne SA, Johnson NM, Qin Y, Witte R, et al. An electrically coupled tissue-engineered cardiomyocyte scaffold improves cardiac function in rats with chronic heart failure. J Heart Lung Transplant 2014;33:438-45.

17. Gao L, Kupfer ME, Jung JP, Yang L, Zhang P, et al. Myocardial Tissue Engineering With Cells Derived From Human-Induced Pluripotent Stem Cells and a Native-Like, High-Resolution, 3-Dimensionally Printed Scaffold. Circ Res 2017;120:1318-25.

18. Wnorowski A, Wu JC. 3-Dimensionally Printed, Native-Like Scaffolds for Myocardial Tissue Engineering. Circ Res 2017;120:1224-6.

19. Menasché P, Vanneaux V, Hagège A, Bel A, Cholley B, et al. Transplantation of Human Embryonic Stem Cell-Derived Cardiovascular Progenitors for Severe Ischemic Left Ventricular Dysfunction. J Am Coll Cardiol 2018;71:429-38.

20. Kawamura M, Miyagawa S, Miki K, Saito A, Fukushima S, et al. Feasibility, safety, and therapeutic efficacy of human induced pluripotent stem cell-derived cardiomyocyte sheets in a porcine ischemic cardiomyopathy model. Circulation 2012;126:S29-37.

21. Schmuck EG, Mulligan JD, Ertel RL, Kouris NA, Ogle BM, et al. Cardiac fibroblast-derived 3D extracellular matrix seeded with mesenchymal stem cells as a novel device to transfer cells to the ischemic myocardium. Cardiovasc Eng Technol 2014;5:119-31.

22. Ruan JL, Tulloch NL, Razumova MV, Saiget VM, Pabon L, et al. Mechanical Stress Conditioning and Electrical Stimulation Promote Contractility and Force Maturation of Induced Pluripotent Stem Cell-Derived Human Cardiac Tissue. Circulation 2016;134:1557-67.

23. Zhang J, Zhu W, Radisic M, Vunjak-Novakovic G. Can we engineer a human cardiac patch for therapy? Circ Res 2018;123:244-65.

24. Akst J. Available from:https://www.the-scientist.com/news-opinion/donor-derived-ips-cells-show-promise-for-treating-eyedisease-65817\#.XMmiehFIHDk.email. [Last accessed on 2 Sep 2019].

25. Fujita B, Zimmermann WH. Myocardial Tissue Engineering for Regenerative Applications. Curr Cardiol Rep 2017;19:78.

26. Pearl JI, Kean LS, Davis MM, Wu JC. Pluripotent stem cells: immune to the immune system? Sci Transl Med 2012;4:164ps25.

27. Cyranoski D. Reprogrammed stem cells approved to mend hearts Japanese study is only the second application of induced pluripotent stem cells in people. Nature 2018;557:619-20.

28. Meissner T, Strominger J, Cowan C. The universal donor stem cell: removing the immune barrier to transplantation using CRISPR/ Cas9 (TRAN1P.946) J Immunol 2015;194:140.28.

29. Gershlaka JR, Hernandez S, Fontanac G, Perreaul LR, Hansen KJ, et al. Crossing kingdoms: Using decellularized plants as perfusable tissue engineering scaffolds. Biomaterials 2017;125:13-22.

30. Liau B, Christoforou N, Leong KW, Bursac N. Pluripotent stem cell-derived cardiac tissue patch with advanced structure and function. Biomaterials 2011;32:9180-7.

31. Kim DH, Kshitiz NV, Smith RR, Kim P, Ahn EH, et al. Nanopatterned cardiac cell patches promote stem cell niche formation and myocardial regeneration. Integr Biol-UK 2012;4:1019-33.

32. Jang J, Park HJ, Kim SW, Kim H, Park JY, et al. 3D printed complex tissue construct using stem cell-laden decellularized extracellular matrix bioinks for cardiac repair. Biomaterials 2017;112:264-74.

33. Tsui JH, Ostrovsky-Snider NA, Yama DMP, Donohue JD, Choi JS, et al. Conductive silk-polypyrrole composite scaffolds with bioinspired nanotopographic cues for cardiac tissue engineering. J Mater Chem B 2018;6:7185-96.

34. Machiraju P, Greenway SC. Current methods for the maturation of induced pluripotent stem cell-derived cardiomyocytes .World J Stem Cells 2019;11:33-43.

35. Lancaster OJ, Sanchez P, Repetti GG, Juneman E, Pandey AC, et al. Human Induced Pluripotent Stem Cell-Derived Cardiomyocyte Patch in Rats With Heart Failure. Ann Thorac Surg 2019; doi: 10.1016/j.athoracsur.2019.03.099.

36. Wei K, Serpooshan V, Hurtado C. Diez-Cuñado M, Zhao M, et al. Epicardial FSTL1 reconstitution regenerates the adult mammalian heart. Nature 2015:525;479-85.

37. Masters M, Riley PR. The epicardium signals the way towards heart regeneration. Stem Cell Res 2014;13:683-92.

38. Cao J, Poss KD. The epicardium as a hub for heart regeneration. Nat Rev Cardiol 2018;15:631-47.

39. Zimmermann WH, Melnychenko I, Wasmeier G, Didié M, Naito H, et al. Engineered heart tissue grafts improve systolic and diastolic function in infarcted rat hearts. Nat Med 2006;12:452-8.

40. Matsubayashi K, Fedak PW, Mickle DA, Weisel RD, Ozawa T, et al. Improved left ventricular aneurysm repair with bioengineered vascular smooth muscle grafts. Circulation 2003;108 Suppl 1:II219-25.

41. Sawa Y, Yoshikawa Y, Toda K, Fukushima S, Yamazaki K, et al. Safety and efficacy of autologous skeletal myoblast sheets (TCD51073) for the treatment of severe chronic heart failure due to ischemic heart disease. Circ J 2015;79:991-9.

42. Yoshikawa Y, Miyagawa S, Toda K, Saito A, Sakata Y, et al. Myocardial regenerative therapy using a scaffold-free skeletal-musclederived cell sheet in patients with dilated cardiomyopathy even under a left ventricular assist device: a safety and feasibility study. Surg Today 2018;48:200-10.

43. Yorgan K, Brenière-Letuffe D, Mannhardt I, Schulze T, Ulmer B, et al. Differentiation of cardiomyocytes and generation of human engineered heart tissue. Nat Protoc 2017;12:1177-97.

44. Liu J, Hu Q, Wang Z, Xu C, Wang X, et al. Autologous stem cell transplantation for myocardial repair. Am J Physiol Heart Circ Physiol 2004;287:H501-11.

45. Godier-Furnemont AF, Martens TP, Koeckert MS, Wan L, Parks J, et al. Composite scaffold provides a cell delivery platform for cardiovascular repair. Proc Natl Acad Sci USA 2011;108:7974-9.

46. Matsuura K, Wada M, Shimizu T, Haraguchi Y, Sato F, et al. Creation of human cardiac cell sheets using pluripotent stem cells. 
Biochem Biophys Res Commun 2012;425:321-7.

47. Sasagawa T, Shimizu T, Sekiya S, Haraguchi Y, Yamato M, et al. Design of prevascularized three-dimensional cell-dense tissues using a cell sheet stacking manipulation technology. Biomaterials 2010;31:1646-54.

48. Jung JH, Fu X, Yang PC. Exosomes generated from iPSC-derivatives: new direction for stem cell therapy in human heart diseases. Circ Res 2017;120:407-17.

49. Ogle BM, Bursac N, Domian I, Huang NF, Menasché P, et al. Distilling complexity to advance cardiac tissue engineering. Sci Transl Med 2016;8:342ps13.

50. Bargher J, Ong L, Colzani M, Davaapil H, Hofsteen P. Epicardial cells derived from human embryonic stem cells augment cardiomyocyte-driven heart regeneration. Nat Biotechnol 2019;37:895-906.

51. Liu YW, Chen B, Yang X, Fugate JA, Kalucki FA, et al. Human embryonic stem cell-derived cardiomyocytes restore function in infarcted hearts of non-human primates. Nat Biotechnol 2018;36:597-605.

52. Romagnuolo R, Masoudpour H, Porta-Sanchez A, Qiang B, Barry J, et al. Human Embryonic Stem Cell-Derived Cardiomyocytes Regenerate the Infarcted Pig Heart but Induce Ventricular Tachyarrhythmias. Stem Cell Rep 2019;12:967-81.

53. Taylor DA. The Future of Tissue Engineering in Heart Transplantation. Tex Heart Inst J 2019;46:73-4.

54. Noor N, Shapira A, Edri R, Gal I, Wertheim L, et al. Tissue Engineering: 3D Printing of Personalized Thick and Perfusable Cardiac Patches and Hearts. Adv Sci 2019;6:1970066.

55. Huang NF, Serpooshan V, Morris VB, Sayed N, Pardon G, et al. Big bottlenecks in cardiovascular tissue engineering. Commun Biol 2018;1:199.

56. Regenerative Medicine Advanced Therapy Designation. Available from:https://www.fda.gov/vaccines-blood-biologics/cellular-genetherapy-products/regenerative-medicine-advanced-therapy-designation. [Last accessed on 2 Sep 2019]. 